\title{
Exploration on Process Evaluation of College English Teaching in Rotating Classroom Mode
}

\author{
Na Sun ${ }^{1, \text { a }}$, Jiapei $\mathrm{Li}^{2, \mathrm{~b}}$ \\ ${ }^{1}$ Teaching and Research Institute of Foreign Languages, Bohai University, Jinzhou, 121013, China \\ ${ }^{2}$ School of Mathematical Science, Dalian University of Technology, Dalian, 116024, China \\ a381104134@qq.com, b271441777@qq.com
}

Keywords: rotating classroom; teaching mode; college English; process evaluation

\begin{abstract}
Teaching evaluation based on the teaching objectives, judging the process and resources of teaching and learning, provide a reliable basis for promoting teachers' teaching and learning. Aiming at the brand-new teaching mode of turning classroom, many college English teachers are puzzled, confused and overwhelmed with the evaluation process and method. Based on the Constructivism Theory and the Second Language Acquisition Theory, this subject analyzes the finality the defects of evaluation and the advantages of procedural evaluation, and focuses on the contents and methods of procedural evaluation of college English in rotating classroom. The research results provide practical solutions for teaching process evaluation, improve teachers' teaching level and help students to improve their learning ability, and promote the overall improvement of college English teaching quality.
\end{abstract}

\section{Introduction}

Jon Bergmann and Aaron Sams quickly became the focus of teaching reform in higher education institutions in the United States after they put forward the teaching model of overturning classrooms based on the technology of "learning from teaching first, learning from teaching after learning", and using technologies such as internet, micro classes and video resources. , But also provides a good experience and reference for the reform of teaching in colleges and universities in our country. Turning classrooms is based on autonomous learning theory, the Constructivism Theory and blended learning theory, readjustment of time inside and outside the classroom, teachers no longer occupy the classroom time to teach information, the decision-making power to transfer learning from the teacher to the students. Students plan their own learning content, learning rhythm, style and presentation of knowledge. Teachers use lecture method and collaboration method to meet the needs of students and facilitate personalized learning. The goal is to enable students to practice more effectively. Turning the classroom to transfer the two processes of learning, in the process of absorbing the internalization, can be transferred from the extracurricular class to the class. In terms of learning effects and knowledge building, the students are mainly based on their actual abilities and foundations, and are in accordance with the principle of teaching students in accordance with their aptitudes. The focus of the classroom is to give the classroom autonomy to students, and teachers simply assist students through assistance and communication, students are free to build their own knowledge system according to their own needs.

Teaching evaluation is based on the teaching objectives of the teaching process and the results of the value judgments and services for teaching decision-making activities, is to teach the actual or potential value of the process to make judgments. Teaching evaluation generally includes the evaluation of teachers, students, teaching content, teaching methods, teaching environment and teaching management factors in the teaching process. Teaching evaluation is an indispensable part of teaching activities. It plays a multifaceted role in the teaching process. It adjusts and controls teaching activities as a whole to ensure that the teaching activities achieve the predetermined goal. Specifically, the teaching evaluation has the effect of testing teaching effectiveness, diagnosing teaching problems, providing feedback information, guiding teaching direction and regulating 
teaching process. College English is a course in which theoretical knowledge and practical skills are closely linked. Skill of listening, speaking, reading, writing and translating is one of the basic qualities of college students. By using rotational classroom teaching mode, we can talk about knowledge before class. In classroom, teachers and students have time to discuss. This can increase students' chances to use language in class, and promote students' Internalization and mastery of language knowledge. Compared with the traditional terminating evaluation method, "procedural evaluation" is more guiding. Process evaluation is not just a process-oriented evaluation method that does not focus on results. On the contrary, the process evaluation focuses on the intelligent development of students in the teaching process results, and be able to make timely and effective judgments on student learning to identify problems and deficiencies, affirming the achievements have been made, at the same time allow students to more clearly the purpose and direction of future learning.

\section{Defects of Finality Evaluation}

Terminology evaluation emphasizes the learning outcomes, ignoring the learning process, learning attitude and learning behavior, etc., can not give full play to evaluate the function of learning. Specific defects are reflected in the following aspects:

(1) Evaluation of the content of defects. Terminology evaluation is too much emphasis on subject knowledge, with particular emphasis on textbook knowledge, neglect of practical ability, innovative spirit, psychological quality, as well as the overall quality of emotions, attitudes and habits. With the advent of social development and the era of network information, it is far from being able to meet the requirements of society for talent development merely by mastered the knowledge and skills. The limitations of academic achievement as a single indicator of student evaluation have become increasingly prominent.

(2) Evaluation standards defects. End-point evaluation overemphasizes commonalities and general trends, ignoring individual differences and individualized development. Each student's hobbies, intelligence and potential are different, the demand for talent in modern society also showed a trend of diversification. Terminating evaluation is based on "standardization", denying individual differences, eliminating the needs of diverse social development such as student personality, hobbies and unique thinking.

(3) Flaws in evaluation methods. The final assessment is based on the examination, and relies too much on the quantitative results. Quantitative assessment is an objective, scientific and rigorous synonym. However, the quantification shows rigid, simplistic and superficial features. The lack of evaluation of the learning process and personality development. The personality characteristics and hard work of students are buried in a group of abstract data, and can not make a comprehensive and correct evaluation, can not promote student development.

(4) Evaluation of the process of defects. Terminating evaluations require students to provide answers only and do not care how to get those answers. The thinking and reasoning of students getting answers, the formation of assumptions and how to apply the evidence are all abandoned in the field of evaluation. Lead students to conclude, ignore the process, do not pay attention to the process of scientific inquiry, help to develop the habit of scientific inquiry and rigorous scientific attitude. Limit the flexibility to solve the problem.

\section{Advantages of Process Evaluation}

Process evaluation uses a variety of evaluation methods and methods to make judgments on the interest, attitude, degree of participation and language development status of the learning process, and continuously evaluate the learning progress. The advantages are reflected in the following aspects:

(1) It reflects the diversity of evaluation subjects and evaluation forms. Process evaluation focuses on the students' whole learning process and all learning experiences, can diagnose the teaching plan, find out the problems in the process of teaching in time, and use the feedback 
information to help students and teachers focus their attention on improving teaching quality.

(2) Pay attention to the learning process. Students in the learning process will take different learning styles, different learning styles will lead to different learning outcomes. Through student self-assessment and mutual assessment, students will be able to grasp the correct way of learning step by step, establish the correct motivation for learning, master the learning strategies suitable for themselves, and truly improve the quality and effectiveness of learning.

(3) Pay attention to unintended results. Process evaluation will be applied to the field of evaluation of students throughout the field of learning experience, any valuable learning outcomes should be affirmed, regardless of the learning outcomes are within the intended goal. As a result, students are motivated to learn more and their learning experience is more enriched.

(4) To highlight the dominant position of students. Change the phenomenon that the teacher is the main body in the English teaching, realize the teaching mode taking student as the main body truly. Through the process of evaluation, continue to promote the content and form of evaluation of diversity, to stimulate students' enthusiasm and interest in learning to play the initiative in learning.

(5) Improve the overall quality of students. While teaching professional knowledge, university education should also pay attention to the cultivation of students' comprehensive quality and the improvement of comprehensive ability. Process evaluation is not only concerned with the evaluation of course learning process, but also focuses on extracurricular learning, cooperative learning and comprehensive learning evaluation to promote good learning habits and self-learning ability development.

\section{Contents of Process Evaluation}

The process evaluation of college English teaching in the context of turning classrooms needs to be carried out from two aspects. One is systematic analysis of the teaching process and the overall evaluation. The other is the observation and evaluation of all aspects and activities of the teaching process.

(1) Teaching process overall evaluation. Take a class or a chapter of teaching objectives and teaching content as a unit, the system analysis and overall evaluation of a complete teaching process such as study before class class teaching, after-school consolidation and seminar summary. Pointing to a certain teaching objectives, teaching content of the teaching process, generally including study before class learning, classroom teaching, after-school consolidation and discussion summed up the four basic links. The four aspects of the teaching activities of system design, forming a cohesion, step by step and gradually improve the teaching process, is to improve the efficiency of teaching an important strategy. However, in the actual teaching work, many teachers often do not pay attention to the various links and the teaching activities of each other. study before class learning, classroom teaching and after-school consolidation appear mismatched and uncoordinated phenomenon. The implementation of the overall evaluation includes the evaluation of all teaching and teaching activities but emphasizes the systematic and integrity of the teaching process. It aims to lead teachers to systematically study and integrate the teaching process and to lead the students' autonomous learning and active development. Cultivate students' learning abilities, practical ability and innovative spirit, taking into account the guidance of the evaluation and feasibility. In addition, the successful implementation of the rotation class relies on the development of learning resources, so it is also an important aspect for teachers to evaluate the ability and level of resource development.

(2) Teaching process evaluation. Evaluation of teaching process evaluation is the teaching process of study before class learning, classroom teaching, after-school consolidation, seminar summary and daily testing and evaluation of teaching activities at all aspects of the observation and evaluation, designed to lead the teachers carefully designed and organized to carry out various teaching activities, Give full play to all aspects of the role. For a long time, people attach great importance to the evaluation of classroom teaching and research, while ignoring the study before class preview, after-school consolidation evaluation and research. School teaching management tend to focus on the assessment of classroom teaching, study before class preview and after-school 
consolidation also rarely clear management measures. Most of the teaching examinations are also aimed at the classroom teaching effect, seldom analyze whether the classroom instructional design is reasonable or not, and pay less attention to the teachers' design and instruction of the study before class preview activities and after-school consolidation. Examining homework exercises often only look at students who did not do it seriously, did teachers review them in time, paid little attention to homework assignments and teacher reviews, and did not even benefit after class and class consolidation. Classroom teaching is the main front of discipline teaching, teaching research and teaching reform should focus on the classroom. However, the classroom can not solve all the problems. Study before class learning with study before class as the main content and after-school learning with consolidation as the main content are important activities that lead students to independently learn and develop their learning abilities. It is also an important part of the teaching process. Also need teachers carefully designed and carefully organized. Also need to strengthen management and evaluation. Especially college English teaching, the memory, deepening and understanding of knowledge need more after-hours, so we must evaluate the whole process of teaching activities to improve the quality of teaching and students ability as the goal, respectively, to study the specific points of observation and Evaluation indicators, the development of operational norms.

\section{Methods of Process Evaluation}

The method of procedural evaluation of college English teaching in rotating classroom mode includes the following two aspects:

(1) To achieve the main diversity of evaluation. Process evaluation emphasizes the diversity of evaluation subjects, and can obtain more comprehensive evaluation information through different feedback channels so that evaluation can truly become the interactive activity in which multiple evaluation subjects actively participate. The teacher evaluation is the most commonly used evaluation method to conduct a comprehensive evaluation of the students 'study before class study, classroom performance and after-school consolidation. Supervising the evaluation of experts is aimed at the evaluation of teachers. The experts are mainly concerned with the preparation of teachers' teaching resources, Class preparation, classroom teaching and classroom organization. An important feature of self-evaluation and procedural evaluation of the evaluation body is that it focuses on the teaching process. Students obtain information about their own learning from the evaluation and continuously reflect on their own learning. Teaching also find out problems existing in the teaching process from the evaluation so as to improve the teaching methods and further promote the teaching. Mutual evaluation of students and mutual evaluation among students is a kind of evaluation activity based on group coordination. Students' self-awareness, cultivating students' qualities and improving students' ability to communicate can play an important role in one-to-one peer evaluation, mutual evaluation of team members and mutual evaluation among teams, but attention should be paid to evaluation Content should be consistent with the goal of student development, evaluation content should be consistent with the age and psychological characteristics of students, evaluation content can guide students to develop in an all-round way; including teacher mutual evaluation and student evaluation of teachers.

(2) Design a variety of evaluation tools. Evaluation tools are important ways and means of carrying out procedural evaluations, and also a direct basis and means for collecting evaluation materials. Designing evaluation tools is the basis and premise for ensuring the effective implementation of procedural evaluations. Process evaluation does not require procedural norms, but rather to be flexible and practical goals. Therefore, the methods and tools of process evaluation can be evaluation forms, questionnaires, classroom observation records, interviews and study portfolios. Various evaluation methods have different evaluation perspectives. A single evaluation method can not fully reflect the teaching level of a teacher and the students' learning situation. Therefore, various evaluation tools should be combined. Design evaluation tools to reflect the diversity of the main evaluation, to facilitate the participation of different subjects in the evaluation. The form of the evaluation form can be either an evaluation form, a list of evaluation items, an 
evaluation concept embodying "qualitative evaluation", and a consideration of diversification of evaluation subjects. The questionnaire is based on respondents' answers to the questionnaire questions Reflect some characteristics of the respondents, to facilitate collation and analysis; classroom observation records, the main teacher can capture the students' attitudes, interests and abilities, supervisory experts can capture the instructor's teaching methods, teaching levels and teaching preparation Situation, etc .; interview information collected by means of direct interview with the interviewee face to face manner, you can also through the forum; learning portfolio for students to learn the achievements of knowledge learned, students can adjust their own Take e-learning portfolio in the learning outcomes, learning performance and other information, according to the selected information to determine their own learning quality and progress.

\section{Conclusion}

The successful application of the research results is not only an important basis for teachers to obtain teaching feedback information, improve teaching management and ensure teaching quality, but also an effective way for students to adjust learning strategies, improve learning methods, improve learning efficiency and achieve good learning outcomes. The teaching reform program of process evaluation of college English teaching in the process of turning classroom teaching can provide theoretical reference and practice basis for the reform of teaching mode of turning classroom in other disciplines of our university and has universal referential significance and important promotion value for further consolidating and deepening teaching reform.

\section{Acknowledgement}

This work is supported by Research subject on teaching reform and educational quality evaluation in Liaoning education evaluation association in June 2017, (PJHYYB17181): Exploration on Process Evaluation of College English Teaching in Rotating Classroom Mode.

\section{References}

[1] Education Department of Liaoning Province, "The reform of classroom teaching mode in Bohai University: turning the classroom," http://www.lnen.cn/jyzx/yxxw/283452.shtml, 2017-8-11.

[2] H. Xu, "Learning Assessment in Comprehensive English Course Innovation by Applying the Process Evaluation Method," Journal of Hubei Correspondence University, vol. 29, no. 22, pp. 138-139, 2016.

[3] Z. C. Zhang, "College English classroom teaching strategies in the context of classroom rotation," Journal of Bohai University(Philosophy \& Social Science Edition), vol. 38, no. 3, pp. 139-140, 2016.

[4] P. Yu, "The application of flipped classroom in English teaching," Teaching \& Adimistration, vol. 21, no. 25, pp. 62-64, 2014.

[5] L. O. Yin, H. Yan, "The application of process assessment in comprehensive English teaching," Knowledge Economy, vol. 19, no. 5, pp. 152-153, 2017.

[6] Y. H. Cui, "Flipped Class Model and Its Application to College English Teaching," China Educational Technology, vol. 35, no. 11, pp. 116-121, 2014.

[7] J. Zhang, "Establishment on indicator system for process evaluation of rotating classroom," Journal of Bohai University (Natural Science Edition), vol. 38, no. 2, pp. 187-192, 2017.

[8] H. M. Zhao, "Study on College English Rotation Class Based on Constructivism," Journal of Liaoning Medical University (Social Science Edition), vol. 14, no. 3, pp. 136-138, 2016. 